\title{
A novel noninstrumented surgical approach for foramen reconstruction for isthmic spondylolisthesis in patients with radiculopathy: preliminary clinical and radiographic outcomes
}

\author{
Jochem K. H. Spoor, MD, ${ }^{1}$ Alof H. G. Dallenga, MD, ${ }^{1}$ Pravesh S. Gadjradj, BSc, ${ }^{1,2}$ \\ Luuk de Klerk, MD, PhD, ${ }^{3}$ Frans C. van Biezen, MD, ${ }^{4}$ Henk W. C. Bijvoet, MD, ${ }^{1}$ and \\ Biswadjiet S. Harhangi, MD, PhD, MSc ${ }^{1}$
}

Departments of ${ }^{1}$ Neurosurgery and ${ }^{4}$ Orthopedics, Erasmus MC: University Medical Center Rotterdam; ${ }^{2}$ Department of Neurosurgery, Leiden University Medical Center, Leiden; and 'Department of Orthopedic Surgery, Sint Maartenskliniek, Nijmegen, The Netherlands

OBJECTIVE The health care costs for instrumented spine surgery have increased dramatically in the last few decades. The authors present a novel noninstrumented surgical approach for patients with isthmic spondylolisthesis, with clinical and radiographic results.

METHODS Charts of patients who underwent this technique were reviewed. The procedure consisted of nerve root decompression by reconstruction of the intervertebral foramen. This was achieved by removal of the pedicle followed by noninstrumented posterolateral fusion in which autologous bone graft from the right iliac crest was used. Outcomes regarding radicular complaints, bony fusion, progression of the slip, and complications were evaluated using patient history and radiographs obtained at follow-up intervals of 3-18 months after surgery.

RESULTS A total of 58 patients with a mean age of 47 years were treated with this method. Partial removal of the pedicle was performed in $93.1 \%$ of the cases, whereas in $6.9 \%$ of the cases the entire pedicle was removed. The mean duration of surgery was $216.5 \pm 54.5$ minutes (range 91-340 minutes). The mean ( \pm SD) duration of hospitalization was $10.1 \pm 2.9$ days (range $5-18$ days).

After 3 months of follow-up, $86 \%$ of the patients reported no leg pain, and this dropped to $81 \%$ at last follow-up. Radiographic follow-up showed bony fusion in $87.7 \%$ of the patients. At 1 year, 5 patients showed progression of the slip, which in 1 patient prompted a second operation within 1 year. No major complications occurred.

CONCLUSIONS Treatment of isthmic spondylolisthesis by reconstruction of the intervertebral neuroforamen and posterolateral fusion in situ is a safe procedure and has comparable results with the existing techniques. Cost-effectiveness research comparing this technique to conventional instrumented fusion techniques is necessary to evaluate the merits for both patients and society.

https://thejns.org/doi/abs/10.3171/2017.10.FOCUS17571

KEY WORDS isthmic spondylolisthesis; foramen reconstruction; radiculopathy; novel surgical technique

I STHMIC spondylolisthesis (IS) is one of the most common types of spondylolisthesis of the lumbar spine, and it manifests with a defect of the pars interarticularis or isthmus causing an anterior slip of the vertebral body. ${ }^{6}$ Isthmic spondylolisthesis usually occurs on L5-
S1 (90\%), but occasionally on higher levels like L4-5 or L3-4 as well. ${ }^{20}$ Presenting signs and symptoms may include those caused by neurological compression or by spinal deformity. The majority of patients with spondylolysis and spondylolisthesis respond to conservative, nonopera-

ABBREVIATIONS ALIF = anterior lumbar interbody fusion; CF = circumferential fusion; FRT = foraminal reconstruction technique; IS = isthmic spondylolisthesis; PLF = posterolateral fusion; PLIF = posterior lumbar interbody fusion; TLIF = transforaminal lumbar interbody fusion.

SUBMITTED August 31, 2017. ACCEPTED October 25, 2017.

INCLUDE WHEN CITING DOI: 10.3171/2017.10.FOCUS17571. 
tive treatment. ${ }^{15}$ If IS causes radiculopathy, it is often explained by narrowing of the neuroforamen, also known as foraminal stenosis.

The anatomical landmarks of the neuroforamen are defined by the upper and lower pedicle on the cranial and caudal part, the facet joint on the posterior part, and the upper and lower vertebral body with the corresponding disc on the anterior part. Foraminal stenosis tends to compromise the nerve exiting below the pedicle of the superiorly located vertebra.

Throughout the years, several surgical options have been described to treat IS. Principles of these techniques include bony decompression, bone fusion, instrumentassisted fusion, and reduction. ${ }^{6}, 10$ In 1955 Gill et al. introduced a novel technique to perform bony decompression without the necessity of instrumented fusion. ${ }^{8}$ This technique consists of the removal of all loose posterior elements and cartilaginous tissue until the nerve is decompressed. A major drawback of this method is the risk of increasing the spinal instability postoperatively.

Nowadays the gold standard surgical procedure to treat IS includes decompression of the nerve root and reduction of the anterior slip, followed by instrumented fusion. ${ }^{6,9}$, 10,19 Apart from the increasing costs of the instrumentation, there are several disadvantages and issues related to instrumented fusion, including adjacent-segment disease, pseudarthrosis, and other potential complications. ${ }^{16}$

We describe an innovative method to decompress the nerve, using a foraminal reconstruction technique (FRT). This was achieved by pedicle removal and posterolateral noninstrumented in situ fusion, without reduction or interbody devices. Preliminary results of this new method are presented and discussed.

\section{Methods}

Charts from a departmental database of patients who underwent the FRT between 1999 and 2016 were reviewed. Patients were eligible for surgery if they had persisting radicular complaints, of which the most important aspect was leg pain causing restrictions on functioning in daily life. This had to occur in the presence of clinical, correlated nerve root compression on MRI at the location of the intervertebral foramen and IS at that lumbar level. For patients to be included in this study, pre- and postoperative imaging had to be available and there had to be a follow-up of at least 3 months.

Medical records were screened for patient parameters, surgical parameters, the effect of treatment on leg and back pain, the presence of complications related to the treatment, and the need for "redo" surgery. Informed consent for undergoing this novel treatment was obtained from all patients. Approval for the study was acquired from the institutional review board of the Erasmus MC: University Medical Center Rotterdam.

\section{Radiographic Assessments}

Anteroposterior and lateral radiographs of the lumbar spine obtained preoperatively were evaluated and compared with radiographs performed at 3 months and up to 18 months postoperatively to evaluate progression of the slip and bone formation. An experienced orthopedic spine surgeon was blinded for any clinical information and evaluated all radiographs at 3 months (L.d.K.) and at the latest follow-up (F.C.v.B.). Progression of the slip was defined as a 1-grade increase of the slip on radiographs at 1 year postsurgery compared with preoperative radiographs.

\section{Surgical Technique}

All patients underwent surgery in the prone position under general anesthesia. Fluoroscopy was used to identify the level at which IS was located, and a median skin incision was performed. The paravertebral muscles were exposed and released from the spinous processes and laminae. After exposing the lamina bilaterally, the loose lamina and corresponding superior articular process were removed. The fibrocartilaginous tissue was excised and the lateral recess was explored to identify the pedicle and the nerve root.

In all patients the nerve was stretched around the pedicle into the neuroforamen. To reconstruct a new, larger neuroforamen, a high-speed drill was used to remove a large, full-width, caudal part of the pedicle until the nerve was fully decompressed. The concept of the procedure is drawn schematically in Fig. 1. After removal of the pedicle, the nerve root migrates cranially to the space that is thereby created. Nerve root decompression was considered to be sufficient if there was no contact of the nerve root with the pedicle anymore. Sometimes total removal of the pedicle was necessary to achieve this. In cases of bilateral radiculopathy, the opposite side was treated likewise.

The bone graft harvested from the right iliac crest was placed posterolaterally on both sides of the transverse process between the upper and lower adjacent segments of the
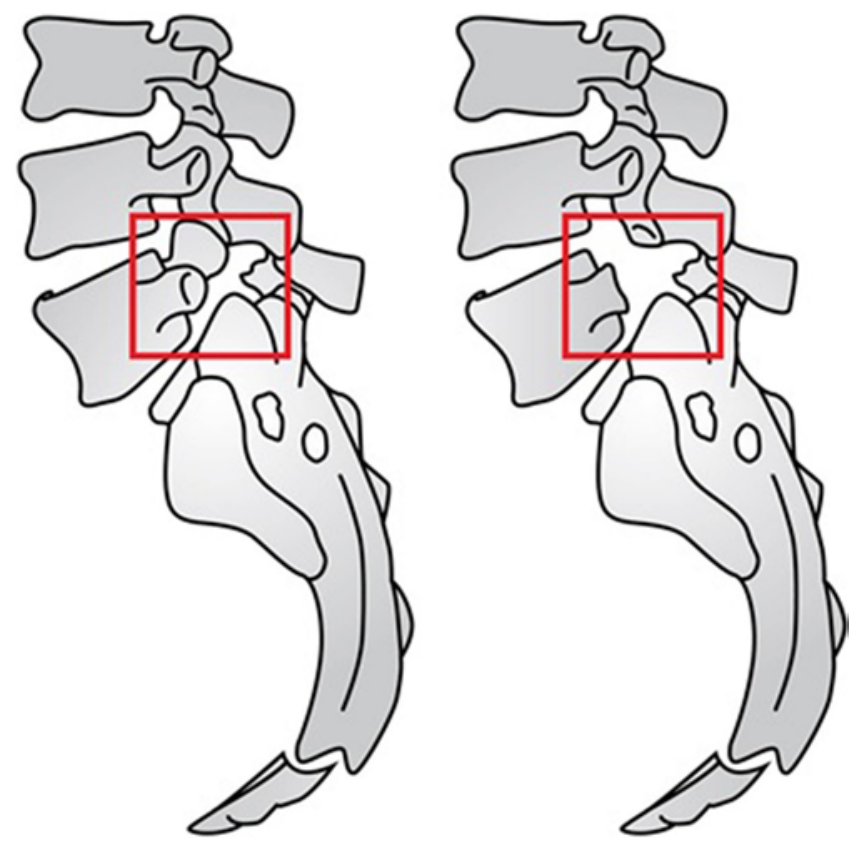

FIG. 1. Drawings of IS in L5-S1. Left: Pedicle in place, fracture of the pars articularis. Right: Pedicle is removed, creating a larger foramen. Copyright Jochem K. H. Spoor. Published with permission. 

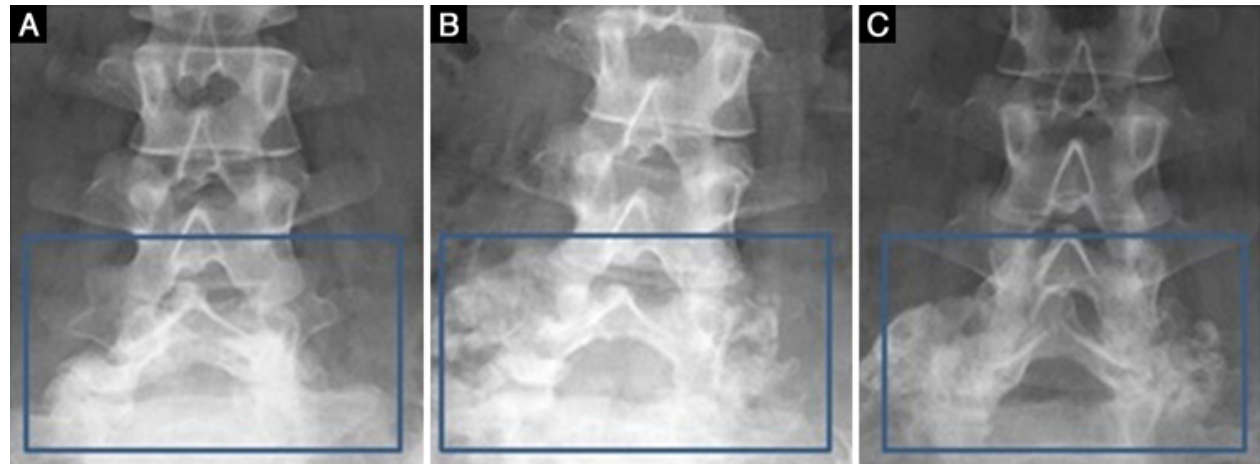

FIG. 2. Anteroposterior radiographs obtained in a woman with a grade III IS in L5-S1. A: Preoperatively. B: At 3 months after surgery, showing bone formation. C: At 1 year after surgery, showing more solid bone formation.

slip. The postoperative treatment consisted of 3 months of immobilization in a plaster cast made of calcined gypsum. The plaster cast included the most affected leg.

To clarify the concept, radiographic results in a 22-yearold woman with grade III IS who was successfully treated with in situ fusion are presented in Figs. 2 and 3. The radiograph obtained after removal of the plaster cast showed fusion and no progression of the slip. A postoperative MRI study showed a successful decompression of the L5 nerve, with CSF and fat surrounding the nerve root (Fig. 4).

\section{Results}

A total of 58 patients were surgically treated using the FRT. Table 1 shows the patient characteristics. The patient population consisted of $25(43.1 \%)$ women and 33 (56.9\%) men, with an average age of 47 years. The level of spondylolisthesis was L5-S1 in 41 (70.7\%) patients and L4-5 in $13(22.4 \%)$ patients. There were $2(3.4 \%)$ patients with IS on L3-4, 1 (1.7\%) on L5-6, and 1 (1.7\%) on level L6-S1.
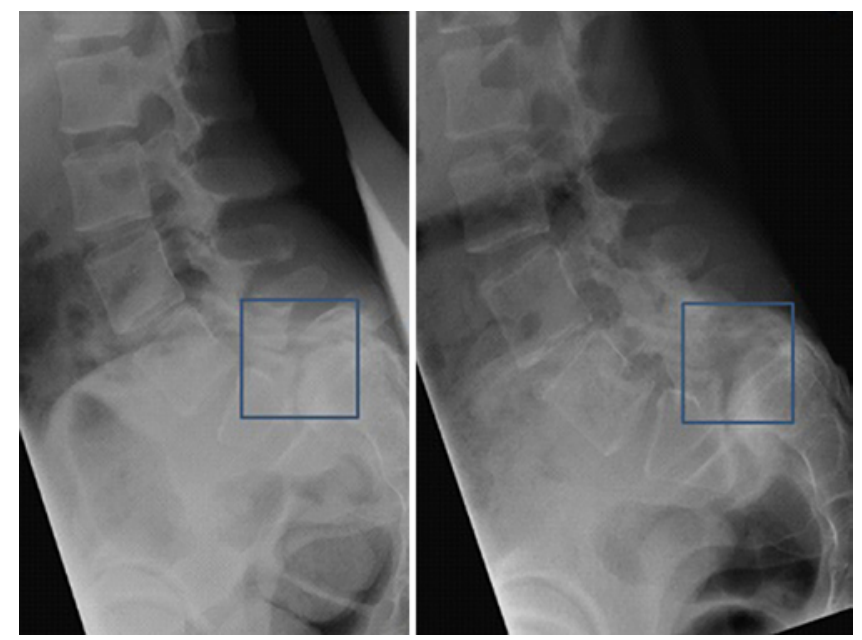

FIG. 3. Lateral radiographs obtained in a woman with a grade III IS in L5-S1, who presented with radiculopathy of her left nerve root in the L-5 area. Left: Before surgery. Right: After surgery, which included removal of the pedicle, laminectomy of $\mathrm{L}-5$, and a spondylodesis in situ. There is no progression of the slip after 1 year and no leg pain.
In $41(70.7 \%)$ patients there was a grade I slip, $16(27.6 \%)$ patients had a grade II slip, and 1 (1.7\%) patient had a grade III slip.

The mean $( \pm$ SD) duration of surgery was $216.5 \pm 54.5$ minutes (range 91-340 minutes) (Table 2). In 54 (93.1\%) of 58 patients the pedicle was removed partially, whereas in $4(6.9 \%)$ patients a total removal of the pedicle was performed. The mean $( \pm \mathrm{SD})$ duration of hospitalization was $10.1 \pm 2.9$ days, and varied from 5 to 18 days. One patient was lost to follow-up, and 3 patients had no data available on leg pain at the most recent visit.

Postoperative wound infection occurred in $3(5.2 \%)$ patients, who were all treated with only antibiotics. One patient had an ulnaropathy directly postoperatively, with tingling in her small finger, probably due to the position of her arm during surgery. One patient received packed red blood cells after surgery because of subsequent bleeding, but no additional surgery had to be performed.

The mean duration of follow-up was 9.1 months (range 2-18 months), and 49 (86\%) of 57 patients had no leg pain at 3 months postoperatively. This dropped to $81 \%$ at the latest follow-up postoperatively. Of the 11 patients who
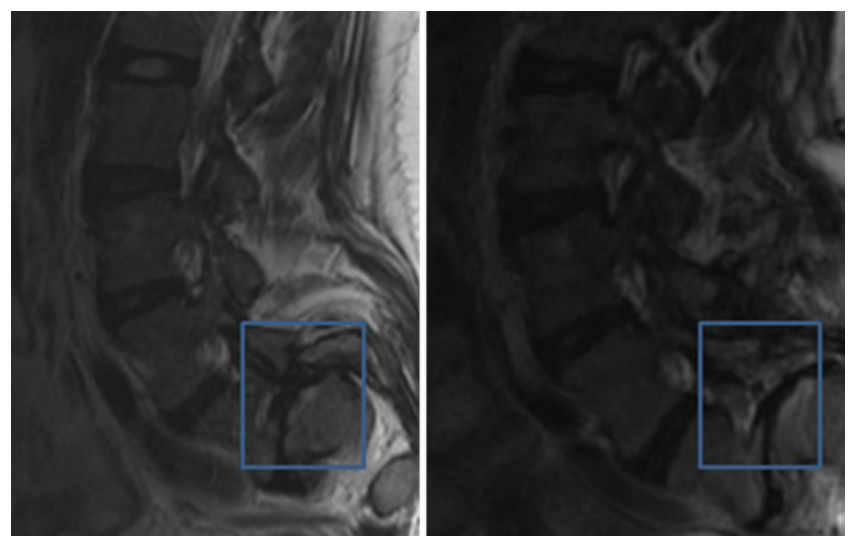

FIG. 4. Preoperative and postoperative MRI studies obtained in a woman with a grade III IS at L5-S1. Left: Preoperative MR image showing narrowing of the neuroforamen L5-S1 on the left side. Right: Postoperative MR image showing the decompressed L5 root on the left side, surrounded by fat and CSF as a sign of decompression. 
TABLE 1. Characteristics in 58 patients with IS

\begin{tabular}{cc}
\hline Characteristic & No. (\%) \\
\hline Sex & \\
\hline Female & $25(43.1)$ \\
\hline Male & $33(56.9)$ \\
\hline Level of listhesis & $2(3.4)$ \\
\hline L3-4 & $13(22.4)$ \\
\hline L4-5 & $1(1.7)$ \\
\hline L5-6 & $41(70.7)$ \\
\hline L5-S1 & $1(1.7)$ \\
\hline L6-S1 & \\
\hline Slip grade & $41(70.7)$ \\
\hline I & $16(27.6)$ \\
\hline III & $1(1.7)$ \\
\hline
\end{tabular}

showed recurrent leg pain at the latest visit after surgery, 1 patient underwent a revision procedure within 1 year. The revision procedure had no effect on the leg pain. Although back pain was not an indication to perform surgery, $72 \%$ of our patients reported a decrease in back pain after surgery.

None of the patients showed progression of the slip at 3 months (Fig. 5). At the last follow-up, 5 patients (8.8\%) showed a $1^{\circ}$ progression of the slip, from grade I to grade II, which in 1 patient prompted a second operation. In 50 (87.7\%) of 57 patients, clear signs of bone formation were present 3 months postoperatively on the radiographs.

\section{Discussion}

We describe a novel technique for the surgical treatment of IS. Our study shows that after we use this technique, $86 \%$ of patients are free of leg pain 3 months after surgery and $81 \%$ remain free of leg pain after a mean follow-up of 9 months. Although back pain was not an indication to perform surgery, $72 \%$ of our patients showed a decrease in back pain after surgery. These results are in agreement with other reports..$^{9,13}$

In $87.7 \%$ of patients there were signs of bone formation on radiographs. In 5 patients there was progression of the slip at the latest follow-up, which was clinically relevant in 1 patient who subsequently underwent a second operation, albeit without improvement.

Our technique has several advantages over instrumented fusion techniques. First, the reconstruction of the neuroforamen creates more space for the nerve due to the removal of the pedicle. In case of subsidence or progressive slip, the nerve will be less prone to bony compression, which is illustrated by the fact that only 1 of 5 patients with progressive slip showed recurrent leg pain requiring a second surgery. The second advantage of this method is that even though there is no use of screws and rods, the $87.7 \%$ bone formation and only $8.8 \%$ progression of slip at the latest visit are both indicative of an acceptable, stable, and solid situation. Malpositioning of screws is no longer a problem. There is no risk of pullout, breakage, or infec-
TABLE 2. Surgical, clinical, and radiographic results in 58 patients with IS

\begin{tabular}{lc}
\hline \multicolumn{1}{c}{ Outcome } & Value \\
\hline Mean duration of op, mins & $216.5 \pm 54.5$, range $91-340$ \\
\hline Pedicle management & $54(93.1 \%)$ \\
\hline \multicolumn{1}{c}{ Partial removal } & $4(6.9 \%)$ \\
\hline Complete removal & $n=5$ \\
\hline Complications & $3(5.2 \%)$ \\
\hline Postop wound infection & $1(1.7 \%)$ \\
\hline Ulnaropathy & $1(1.7 \%)$ \\
\hline Subsequent bleeding w/o need & \\
\hline for op & $10.1 \pm 2.9$, range $5-18$ \\
\hline Mean length of hospital stay, days & 49 of $57(86 \%)$ \\
\hline Free of leg pain at 3-mo follow-up* & 50 of $57(87.7 \%)$ \\
\hline Bone formation occurred &
\end{tabular}

Values are expressed as the mean \pm SD or the number of patients (\%).

* Information was missing in 1 patient.

tion of the screws, and removal of implants is no issue with this technique. The third advantage is that no hardwarerelated artifacts will be seen on postoperative MRI. This will have important clinical relevance when correlating the MRI to new or recurrent complaints.

The next advantage is that the bone graft material is placed on the transverse process; hence, little or no bone formation will occur posteriorly, which supports a relatively easy surgical access if future spine surgery should be necessary. Another advantage is the cost-effectiveness of the FRT over instrumented fusion techniques. When we look at the trends in the surgical management of IS in the US, the rate of fusion surgeries has increased from 28.31 surgeries in 1998 to 122.69 surgeries in 2011 per million

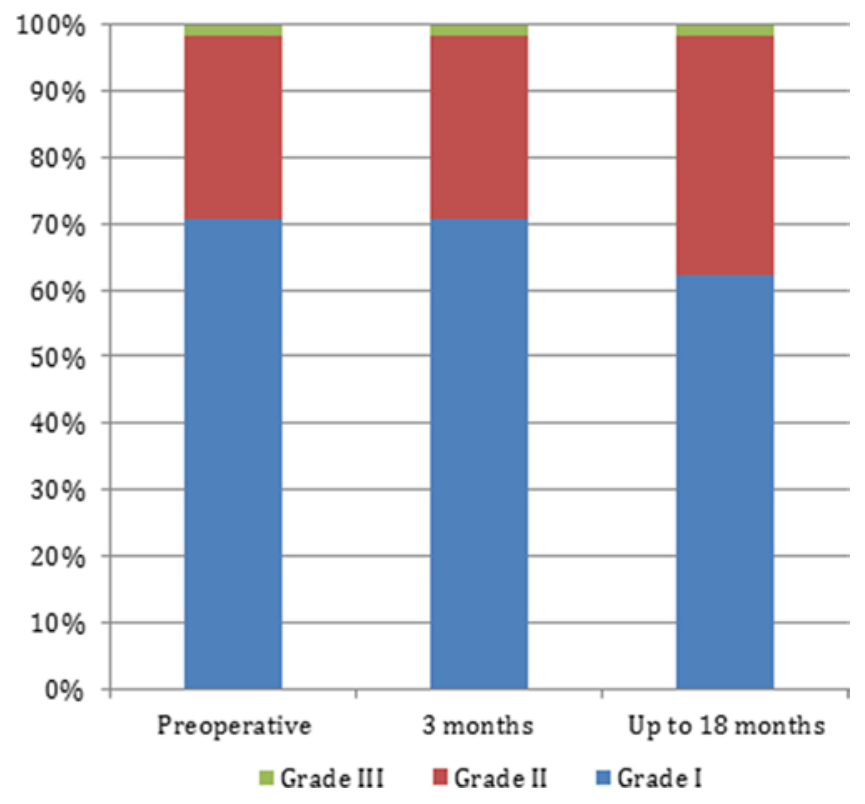

FIG. 5. Bar graph showing the degree of the vertebral slip pre- and postoperatively. 
adults per year. ${ }^{18}$ Similarly in that period, the use of posterior transforaminal lumbar interbody fusion (TLIF) has increased the most (4.33 times). The increased cost for the health care due to the use of implants can perhaps be halted by the use of noninstrumented fusion techniques. Finally, patients can now also be offered the choice of another, noninstrumented fusion technique to treat IS.

A major disadvantage of noninstrumented fusion is that the patient is immobilized postoperatively in a plaster cast for 3 months, including the most affected leg. Next, in harvesting bone from the iliac crest, graft site pain is the most frequently reported donor site morbidity. However, recently it has been shown that patients are not capable of distinguishing which iliac crest was used for the autograft, which implies that donor site morbidity may not be as relevant as was initially thought. ${ }^{14}$ Finally, no randomized data are available to compare this technique to the gold standard.

There are several limitations to our study. Due to its retrospective nature, evaluation of outcome was limited to self-reported pain. Standardized pain evaluations completed using patient-reported outcome measures were not used. Furthermore, our study includes only 1 patient with a grade III slip, which affects the generalizability of our results. Another limitation of this study is the short length of follow-up; namely, a mean follow-up of 9.1 months with a range of 2-18 months. Prospective studies using patientreported outcome measures with longer follow-up are therefore necessary to show the effectiveness of the FRT on radiculopathy and on preventing progression of the slip.

Reporting and sampling bias are a major concern in this study. However, our aim was to show that treatment of IS by using in situ fusion combined with pedicle removal is in agreement with results found in the literature, in which conventional instrumented fusion techniques were used.

Several surgical techniques for IS have been compared thus far, but mostly without any statistically significant differences. ${ }^{3,4,9-12}$ A systematic review was performed comparing anterior lumbar interbody fusion (ALIF), TLIF, posterior lumbar interbody fusion (PLIF), posterolateral fusion (PLF), and circumferential fusion (CF) in the treatment of IS. In this review, CF showed the highest fusion rate, TLIF resulted in fewer complications, and the best sagittal alignment was achieved using ALIF. ${ }^{19}$ Due to methodological differences in the studies, no recommendations were given regarding the optimal approach.

Recently, a meta-analysis of randomized controlled trials comparing instrumented and noninstrumented fusion in isthmic and degenerative spondylolisthesis was published. ${ }^{21}$ The authors found a significantly higher fusion rate after instrumented procedures, but there was no significant difference in patient-reported clinical outcome.

The use of instrumented versus noninstrumented fusion in the spine has been an area for many discussions. ${ }^{2,5}$, 7,17 Recently, a systematic review concluded that instrumented fusion with decompression appeared to be more successful than decompression alone in the treatment of degenerative spondylolisthesis, albeit with poor evidence. ${ }^{17}$ This conclusion, however, could not be confirmed by a robust randomized controlled trial. ${ }^{5}$ Similarly, perhaps instrumented fusion techniques may not show the additional value in clinical outcomes over noninstrumented fusion techniques.

Cost-effectiveness is a growing concern in health care, and it is even more so in instrumented spine surgery. A study on the cost-effectiveness of PLF versus PLIF/TLIF in lumbar IS and degenerative spondylolisthesis showed PLF being moderately more cost-effective in the long run. ${ }^{1}$ Because our surgical technique has similar results compared with instrumented procedures, the cost-effectiveness of the treatment of IS should be the subject of debate. A randomized trial for a comparison of the instrumented and the noninstrumented techniques for clinical and radiographic outcomes and for cost-effectiveness is indicated for the near future.

\section{Conclusions}

Treatment of IS by reconstruction of the intervertebral neuroforamen and PLF in situ is a safe procedure and has comparable results with the existing techniques. Costeffectiveness research comparing this technique to conventional instrumented fusion is necessary to evaluate the merits for both patients and society.

\section{References}

1. Bydon M, Macki M, Abt NB, Witham TF, Wolinsky JP, Gokaslan ZL, et al: The cost-effectiveness of interbody fusions versus posterolateral fusions in 137 patients with lumbar spondylolisthesis. Spine J 15:492-498, 2015

2. de Rooij JD, Gadjradj PS, Huygen FJ, Luijsterburg PA, Harhangi BS: Management of symptomatic cervical disk herniation: a survey among Dutch neurosurgeons. Spine (Phila Pa 1976) 42:311-317, 2017

3. Ekman P, Möller H, Tullberg T, Neumann P, Hedlund R: Posterior lumbar interbody fusion versus posterolateral fusion in adult isthmic spondylolisthesis. Spine (Phila Pa 1976) 32:2178-2183, 2007

4. Farrokhi MR, Rahmanian A, Masoudi MS: Posterolateral versus posterior interbody fusion in isthmic spondylolisthesis. J Neurotrauma 29:1567-1573, 2012

5. Försth P, Ólafsson G, Carlsson T, Frost A, Borgström F, Fritzell P, et al: A randomized, controlled trial of fusion surgery for lumbar spinal stenosis. N Engl J Med 374:1413-1423, 2016

6. Ganju A: Isthmic spondylolisthesis. Neurosurg Focus 13(1):E1, 2002

7. Ghogawala Z, Dziura J, Butler WE, Dai F, Terrin N, Magge $\mathrm{SN}$, et al: Laminectomy plus fusion versus laminectomy alone for lumbar spondylolisthesis. N Engl J Med 374:14241434,2016

8. Gill GG, Manning JG, White HL: Surgical treatment of spondylolisthesis without spine fusion; excision of the loose lamina with decompression of the nerve roots. J Bone Joint Surg Am 37-A:493-520, 1955

9. Kim NH, Lee JW: Anterior interbody fusion versus posterolateral fusion with transpedicular fixation for isthmic spondylolisthesis in adults. A comparison of clinical results. Spine (Phila Pa 1976) 24:812-817, 1999

10. Lee GW, Lee SM, Ahn MW, Kim HJ, Yeom JS: Comparison of posterolateral lumbar fusion and posterior lumbar interbody fusion for patients younger than 60 years with isthmic spondylolisthesis. Spine (Phila Pa 1976) 39:E1475-E1480, 2014

11. McGuire RA, Amundson GM: The use of primary internal fixation in spondylolisthesis. Spine (Phila Pa 1976) 18:1662-1672, 1993 
12. Möller H, Hedlund R: Instrumented and noninstrumented posterolateral fusion in adult spondylolisthesis: a prospective randomized study: part 2. Spine (Phila Pa 1976) 25:17161721,2000

13. Möller H, Hedlund R: Surgery versus conservative management in adult isthmic spondylolisthesis: a prospective randomized study: part 1. Spine (Phila Pa 1976) 25:1711-1715, 2000

14. Pirris SM, Nottmeier EW, Kimes S, O'Brien M, Rahmathulla G: A retrospective study of iliac crest bone grafting techniques with allograft reconstruction: do patients even know which iliac crest was harvested? Clinical article. J Neurosurg Spine 21:595-600, 2014

15. Pizzutillo PD, Hummer CD III: Nonoperative treatment for painful adolescent spondylolysis or spondylolisthesis. J Pediatr Orthop 9:538-540, 1989

16. Sakaura H, Yamashita T, Miwa T, Ohzono K, Ohwada T: Symptomatic adjacent segment pathology after posterior lumbar interbody fusion for adult low-grade isthmic spondylolisthesis. Global Spine J 3:219-224, 2013

17. Schulte TL, Ringel F, Quante M, Eicker SO, Muche-Borowski C, Kothe R: Surgery for adult spondylolisthesis: a systematic review of the evidence. Eur Spine J 25:2359-2367, 2016

18. Thirukumaran CP, Raudenbush B, Li Y, Molinari R, Rubery $\mathrm{P}$, Mesfin A: National trends in the surgical management of adult lumbar isthmic spondylolisthesis: 1998 to 2011. Spine (Phila Pa 1976) 41:490-501, 2016

19. Wang SJ, Han YC, Liu XM, Ma B, Zhao WD, Wu DS, et al: Fusion techniques for adult isthmic spondylolisthesis: a systematic review. Arch Orthop Trauma Surg 134:777-784, 2014

20. Wiltse LL, Winter RB: Terminology and measurement of spondylolisthesis. J Bone Joint Surg Am 65:768-772, 1983
21. Ye YP, Chen D, Xu H: The comparison of instrumented and non-instrumented fusion in the treatment of lumbar spondylolisthesis: a meta-analysis. Eur Spine J 23:1918-1926, 2014

\section{Disclosures}

The authors report no conflict of interest concerning the materials or methods used in this study or the findings specified in this paper.

\section{Author Contributions}

Conception and design: Harhangi, Spoor, Dallenga. Acquisition of data: Harhangi, Spoor, Dallenga, Gadjradj, van Biezen, Bijvoet. Analysis and interpretation of data: Harhangi, Spoor, Gadjradj, de Klerk. Drafting the article: Harhangi, Spoor, Gadjradj, de Klerk. Critically revising the article: Harhangi, Spoor, Dallenga, Gadjradj. Reviewed submitted version of manuscript: all authors. Approved the final version of the manuscript on behalf of all authors: Harhangi. Statistical analysis: Spoor, Gadjradj. Administrative/technical/material support: Harhangi, Dallenga, de Klerk, van Biezen, Bijvoet. Study supervision: Harhangi.

\section{Supplemental Information \\ Videos}

Video Abstract. https://vimeo.com/245925430.

\section{Correspondence}

Biswadjiet S. Harhangi: Erasmus MC, University Medical Center Rotterdam, The Netherlands. b.s.harhangi@erasmusmc.nl. 